Article

\title{
Design and Fabrication of the Reliable GaN Based Vertical-Cavity Surface-Emitting Laser via Tunnel Junction
}

\author{
Chih-Chiang Shen ${ }^{1}$, Yun-Ting Lu ${ }^{1}$, Yen-Wei Yeh ${ }^{1}{ }^{\mathbb{D}}$, Cheng-Yuan Chen $^{1}$, Yu-Tzu Chen ${ }^{1}$, \\ Chin-Wei Sher ${ }^{1,2}$, Po-Tsung Lee ${ }^{1}$, Ya-Hsuan Shih ${ }^{3}$, Tien-Chang Lu ${ }^{1}$, Tingzhu Wu ${ }^{4, *}$, \\ Ching-Hsueh Chiu ${ }^{1, *}$ and Hao-Chung Kuo ${ }^{1, *}$
}

1 Department of Photonics and Institute of Electro-Optical Engineering, College of Electrical and Computer Engineering, National Chiao Tung University, Hsinchu 30010, Taiwan; justin.shen62@gmail.com (C.-C.S.); s102328032@mail1.ncnu.edu.tw (Y.-T.L.); fredyeh.eo06g@g2.nctu.edu.tw (Y.-W.Y.);

a96561@gmail.com (C.-Y.C.); s103328018@mail1.ncnu.edu.tw (Y.-T.C.); steven.sher@hotmail.com (C.-W.S.); potsung@mail.nctu.edu.tw (P.-T.L.); timtclu@mail.nctu.edu.tw (T.-C.L.)

2 Fok Ying Tung Research Institute, Hong Kong University of Science and Technology, Hong Kong 511458, China

3 Crosslight Software Inc., Taiwan Branch, Hsinchu 30013, Taiwan; miashih@crosslight.com.tw

4 Department of Electronic Science, Fujian Engineering Research Center for Solid-State Lighting, Xiamen University, Xiamen 361005, China

* Correspondence: wutingzhu@xmu.edu.cn (T.W.); jimchiu@nctu.edu.tw (C.-H.C.); hckuo@faculty.nctu.edu.tw (H.-C.K.)

Received: 4 March 2019; Accepted: 27 March 2019; Published: 1 April 2019

\begin{abstract}
In this study, we theoretically designed and experimentally fabricated an InGaN vertical-cavity surface-emitting laser (VCSEL) with a tunnel junction (TJ) structure. From numerical simulation results, the optical loss of the device can be reduced by a TJ structure. Additionally, the leakage current of the VCSEL with TJ structure was much smaller than that of the VCSEL with an Indium-Tin-Oxide (ITO) layer. We have been demonstrated that laser output performance is improved by using the TJ structure when compared to the typical VCSEL structure of the ITO layer. The output power obtained at $2.1 \mathrm{~mW}$ was enhanced by a factor of 3.5 by the successful reduction of threshold current density $\left(\mathrm{J}_{\text {th }}\right)$ from 12 to $8.5 \mathrm{kA} / \mathrm{cm}^{2}$, and the enlarged slope efficiency was due to less absorption in VCSEL with a TJ structure. Finally, the samples passed the high temperature $\left(70{ }^{\circ} \mathrm{C}\right)$ and high operation current $\left(1.5 \times \mathrm{J}_{\text {th }}\right)$ test for over $500 \mathrm{~h}$.
\end{abstract}

Keywords: InGaN; VCSEL; tunnel junction

\section{Introduction}

The GaN-based material system features high emission efficiency with the characteristic of direct-bandgap, whose emission wavelength can cover the overall visible light spectrum by tuning alloy compositions [1-4]. These advantages enable these materials to have many potential applications. On the other hand, compared to edge-emitting lasers and light-emitting diodes (LEDs), vertical-cavity surface-emitting lasers (VCSELs) have the superiority of low power consumption, circular beam shape, high modulation response, and low divergence angles [5-8]. Armed with these attributes, GaN-based VCSELs are destined to replace conventional LEDs and lasers as light sources in many applications, including optical storage, laser printers, projectors, displays, solid-state lighting, and visible light communications. If green and blue forms of this device are united with red-emitting GaAs VCSELs, this could spawn incredibly small, wearable projectors for full-color displays [9-12]. 
Our group demonstrated the first electrically pumped GaN-based VCSEL at 77K in 2008, it was realized with a high quality epitaxial bottom $\mathrm{AlGaN} / \mathrm{GaN}$ distributed Bragg reflector (DBR) on c-plane sapphire, by inserting superlattice structure to release the strain. The emission wavelength was $462 \mathrm{~nm}$ with a $1.4 \mathrm{~mA}$ threshold current and a $10 \mathrm{um} \mathrm{SiO}_{2}$ defined current aperture [13]. In 2009, Nichia corp. exhibited a GaN-VCSEL on GaN substrate with top/bottom dielectric DBR, they used a complicate bonding process to avoid the use of epitaxial DBR layers [14]. However, the threshold current was comparatively high, at $7 \mathrm{~mA}$. In 2010, we further improved the performance of VCSEL on sapphire by placing the Indium-Tin-Oxide layer (ITO) current spreading layer at the optical field node, which can significantly reduce the loss of light [15]. In the structure, the laser has a thin Indium-Tin-Oxide layer of $30 \mathrm{~nm}$ as the transparent conducting layer combining with a thin heavily doped p-type InGaN contact layer to reduce the optical loss while maintaining good current spreading capability. An AlGaN electric blocking layer on the top of the InGaN multiple quantum well is also inserted to prevent the carrier overflow [16]. Above the threshold current, the laser has a threshold current of $9.7 \mathrm{~mA}$ corresponding to $12.4 \mathrm{kA} / \mathrm{cm}^{2}$. The laser emission wavelength is $412 \mathrm{~nm}$ with a linewidth of about $0.5 \mathrm{~nm}$. The laser has an estimated spontaneous emission coupling factor of about $5 \times 10^{-3}$. In general, the indium tin oxide (ITO) has been the most commonly used material to improve lateral current spreading on the p-side of the VCSEL device. However, the high absorption loss of ITO can lead to significantly higher threshold currents and lower light outputs $[17,18]$. In this work, the numerical simulation was performed via Crosslight software Photonic Integrated Circuit Simulator in 3D (PICS3D) on tunnel junction (TJ) structure GaN VCSELs [19-21] as well as an ITO based VCSEL which we had used before [16]. The experimental and modeling results demonstrate that laser output performance is improved by using the TJ structure when compared to the typical VCSEL structure of the ITO layer.

\section{Experiments}

The structure of a conventional InGaN-based VCSEL, used as a reference in this study, was grown on a c-plane sapphire substrate by a metal-organic chemical vapor deposition (MOCVD) system. The subsequent epitaxial structure consisted of a $30 \mathrm{~nm}$ thick GaN nucleation layer, 25 pairs of AlN/GaN DBRs with $\lambda / 4 \mathrm{n}$ (n denotes the refractive index, and $\mathrm{n}$ for $\mathrm{AlN}$ is 2.1, while $\mathrm{n}$ for $\mathrm{GaN}$ is 2.4) thickness of each layer, a $790 \mathrm{~nm}$ thick n-type GaN layer (n-doping $=5 \times 10^{18} \mathrm{~cm}^{-3}$ ), ten pairs of $\operatorname{In}_{0.1} \mathrm{Ga}_{0.9} \mathrm{~N}$ $(2.5 \mathrm{~nm}) / \mathrm{GaN}(10 \mathrm{~nm})$ multi-quantum wells $(\mathrm{MQWs})$, followed by a $25 \mathrm{~nm}$ thick $\mathrm{p}-\mathrm{Al}_{0.25} \mathrm{Ga}_{0.75} \mathrm{~N}$ electron blocking layer (EBL) (p-doping $=3 \times 10^{17} \mathrm{~cm}^{-3}$ ), and a $120 \mathrm{~nm}$ thick p-type GaN layer ( $\mathrm{p}$-doping $=5 \times 10^{17} \mathrm{~cm}^{-3}$ ). The location of the MQWs was designed at the anti-node of the standing wave to enhance the coupling efficiency and confinement factor. The thickness of the resonant cavity was $7 \lambda$. In the fabrication process, a $200 \mathrm{~nm}$ thick SiNx layer was deposited by plasma-enhanced chemical vapor deposition (PECVD) as a current-confined layer. In this way, the current injection aperture was designed to be about $5 \mu \mathrm{m}$ in diameter. Then, a $40 \mathrm{~nm}$ thick indium-tin-oxide (ITO) layer was deposited as the current spreading layer and annealed at $600{ }^{\circ} \mathrm{C}$ for $10 \mathrm{~min}$ by rapid thermal annealing (RTA). Then, the p-contact and n-contact were deposited with $\mathrm{Ni} / \mathrm{Au}$ of about $20 \mathrm{~nm} / 150 \mathrm{~nm}$ and $\mathrm{Ti} / \mathrm{Al} / \mathrm{Ni} / \mathrm{Au}$ of about $20 \mathrm{~nm} / 150 \mathrm{~nm} / 20 \mathrm{~nm} / 150 \mathrm{~nm}$ by the E-gun system, respectively. Finally, ten pairs of $\mathrm{Ta}_{2} \mathrm{O}_{5} / \mathrm{SiO}_{2}$ of the top dielectric DBRs were deposited by the ion-assisted E-gun system, to complete the whole InGaN-based VCSEL devices. Both the 25 pairs AlN/GaN DBR and the ten pairs of $\mathrm{Ta}_{2} \mathrm{O}_{5} / \mathrm{SiO}_{2}$ DBR showed a high reflectivity over $99 \%$ at the peak wavelength at $410 \mathrm{~nm}$ in the n-k measurement system. The TJ structure consisted of $30 \mathrm{~nm}$ p++-GaN, $40 \mathrm{~nm}$ n++-GaN, $100 \mathrm{~nm}$ n-GaN, and $30 \mathrm{~nm} \mathrm{n+-GaN} \mathrm{with} \mathrm{a} \mathrm{Si} \mathrm{doping} \mathrm{concentration} \mathrm{of} \mathrm{approximately} 1 \times 10^{20} \mathrm{~cm}^{-3}, 1.8 \times 10^{19} \mathrm{~cm}^{-3}$, $3.2 \times 10^{18} \mathrm{~cm}^{-3}$ or $1 \times 10^{19} \mathrm{~cm}^{-3}$. Figure 1 shows the schematic diagram of the InGaN-based VCSEL structure with ITO and TJ structure in this specific study. 
(a)

(b)

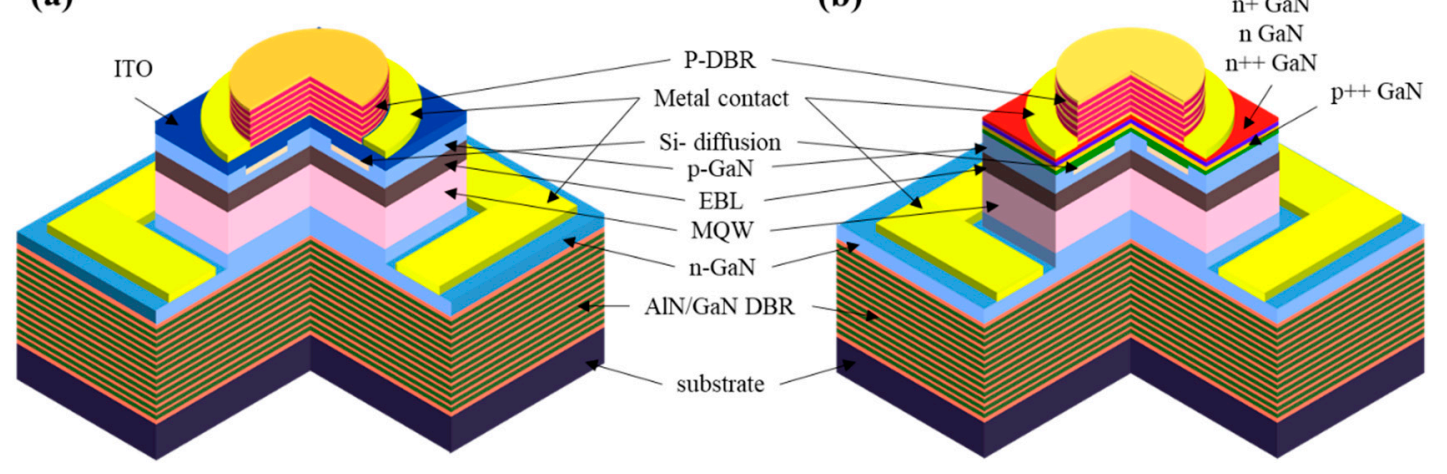

Figure 1. Schematic of GaN-based VCSEL structures with (a) ITO and (b) TJ structure.

\section{Theoretical Models}

To investigate the effects of using TJ structure [22-25], and to further analyze the carrier transport and distribution within the MQW active region of the InGaN-based VCSELs, an advanced simulator PICS3D was utilized in this specific study. The PICS3D is based on three-dimensional finite element analysis and can deal with the optical and electrical properties of optoelectronic devices by solving Poisson's equation, current continuity equations, carrier transport equations, complex wave equations, and photon rate equations. The carrier transport model includes the drift and diffusion of electrons and holes in semiconductors. For VCSELs, the carrier-transport and Poisson equations are solved in a cylindrical coordinate system. Built-in polarization induced by spontaneous and piezoelectric polarization is considered at hetero-interfaces of nitride-based devices. In the optical mode model, a basic scalar complex wave equation is solved for the lateral modes, while the effective index method is chosen for the calculation of the optical lateral modes in VCSELs. The method decouples the optical fields in both the vertical and the transverse directions [26].

\section{Results and Discussions}

Figure 2 shows the refractive index and the standing wave profiles for VCSELs with ITO and TJ structures, respectively. The blue line is the distribution of refractive index for VCSEL while the black line is the distribution of standing wave profile for VCSELs. We designed the location of ITO at the node of the standing wave to reduce optical loss for ITO absorption. The absorption coefficient of $30 \mathrm{~nm} \mathrm{p}+\mathrm{GaN}$ and $40 \mathrm{~nm} \mathrm{n}+\mathrm{GaN}$ layer are $10^{2} \mathrm{~cm}^{-1}$. The absorption coefficient of $40 \mathrm{~nm}$ ITO layer is $10^{3} \mathrm{~cm}^{-1}$. Therefore, the optical loss of the VCSEL device is reduced efficiently using TJ structure. Therefore, the intensity of the standing wave is reduced at the location of ITO as shows in Figure 2a. On the other hand, the standing wave intensity loss is decreased at the location of TJ structure. Thus, the optical loss of the VCSEL device is reduced efficiently by using the TJ structure.

The lateral leakage current density of VCSELs with ITO and TJ structures at $10 \mathrm{~mA}$ are shown in Figure 3, respectively. The x-axis starts from the reference position (which is the center axis of the VCSEL) and goes out along the ITO or TJ layer. We can observe that the current distribution was nonuniform for the VCSEL device with ITO because leakage current exists in the area with a radius of $9 \mu \mathrm{m}$ from the central axis. In contrast, the current distribution is uniform for the VCSEL device with TJ and concentrated within a radius of only $3 \mu \mathrm{m}$ from the central axis. In addition, the leakage current of VCSEL device with TJ structure $\left(4500 \mathrm{~A} / \mathrm{cm}^{2}\right)$ is less than that with ITO $\left(70,000 \mathrm{~A} / \mathrm{cm}^{2}\right)$. 

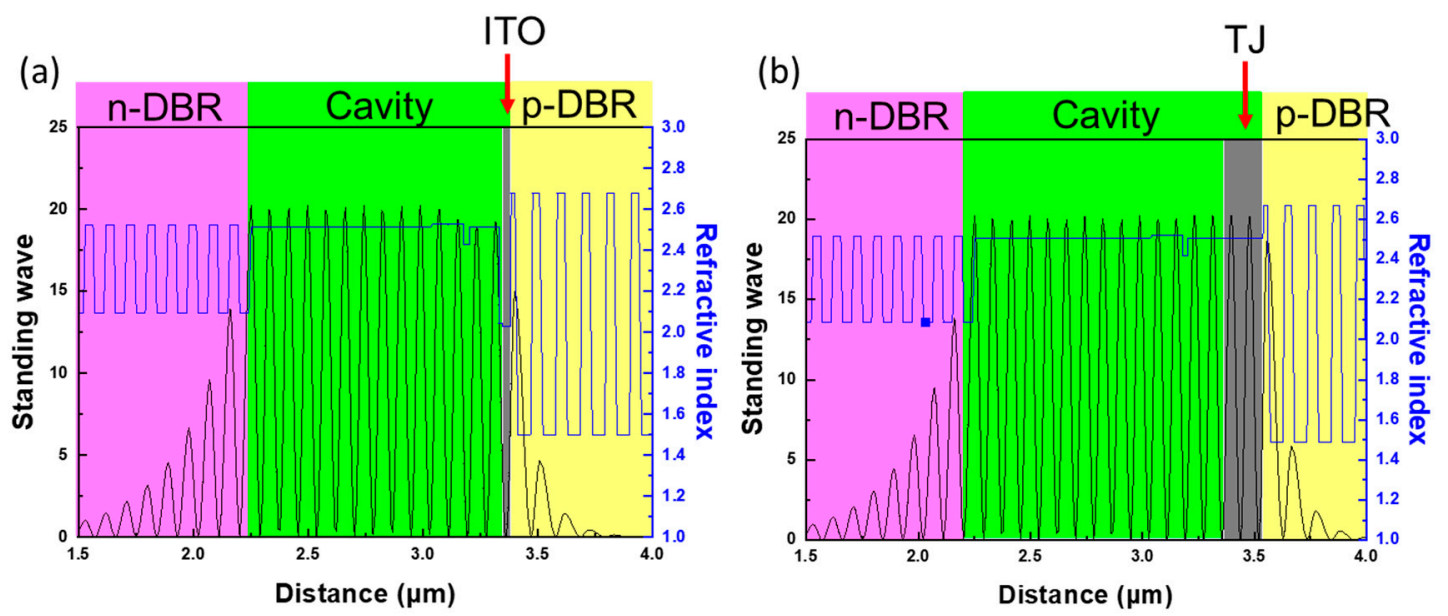

Figure 2. Refractive index and standing wave profile for VCSELs with (a) ITO and (b)TJ structures.
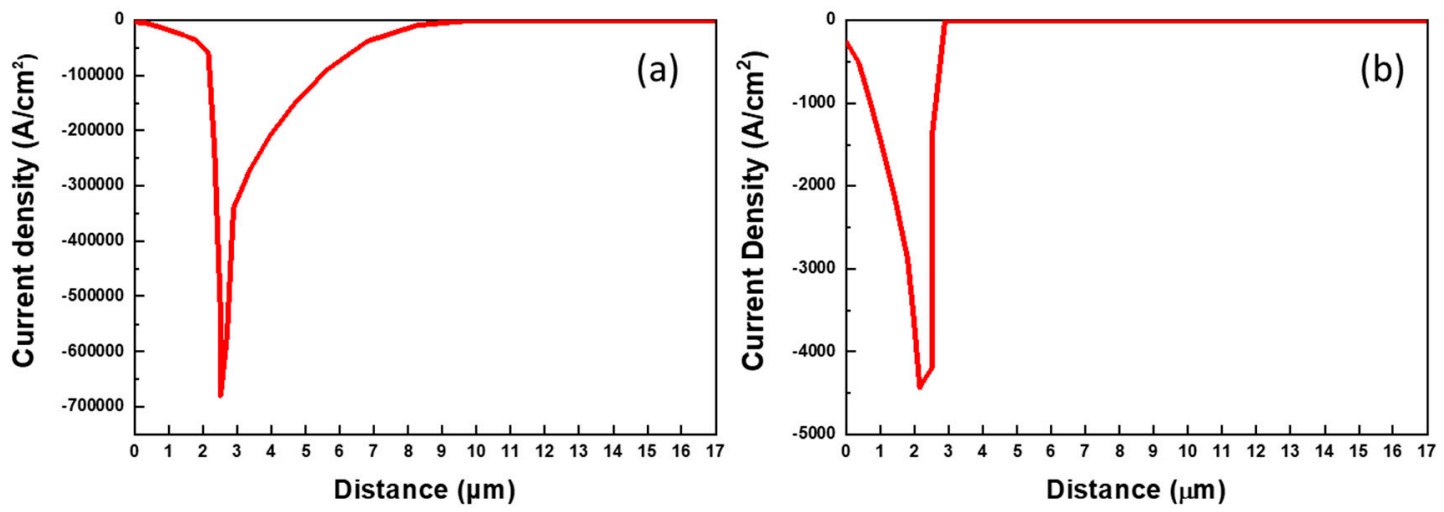

Figure 3. Lateral leakage current density near the (a) ITO and (b) TJ structures at 10mA.

The experimental and simulative results of the output power of VCSEL devices with ITO and TJ structures are shown in Figure 4a. The results were obtained at $300 \mathrm{~K}$ under continuous wave current injection. It was apparent that experimental results and simulative results are consistent with each other, for both ITO and TJ structures. Moreover, the threshold current density was reduced from 12 to $8.5 \mathrm{kA} / \mathrm{cm}^{2}$ and the slope efficiency was improved when the TJ structure was utilized because of the less optical loss within TJ structure region. Accordingly, the laser output power can be increased from $0.6 \mathrm{~mW}$ to $2.1 \mathrm{~mW}$ (improving to $350 \%$ ) with a current of $10 \mathrm{~mA}$. Curves between voltage and current density are demonstrated in Figure $4 \mathrm{~b}$, and the turn-on voltage for VCSEL with TJ structure $(4.9 \mathrm{~V})$ was higher than with ITO layer $(4 \mathrm{~V})$. The series resistance of device can be increased using TJ structure. However, the VCSEL with a TJ structure performs better than that with ITO layer because the former has a better power output and can reduce the threshold current density.

The VCSEL device reliability is a very important issue for many practical applications. It is the strongly desirable feature for parallel optics applications. In the following, we observed the performance of the high temperature operating life (HTOL) stress test $\left(70^{\circ} \mathrm{C} / 1.5 \times \mathrm{J}_{\text {th }}\right)$ of both VCSEL devices are shown in Figure 5. It was obvious that there are 6 failure devices for VCSEL with ITO structure while all VCSEL devices with the TJ structure worked well after $500 \mathrm{~h}$. Therefore, the TJ structure not only can greatly improve the electrical and optical properties but also can successfully maintain the device performance. The degradation of VCSELs with ITO structure might be attributed to the ITO/p-GaN interface during high driving condition. Further investigations shall be performed. 

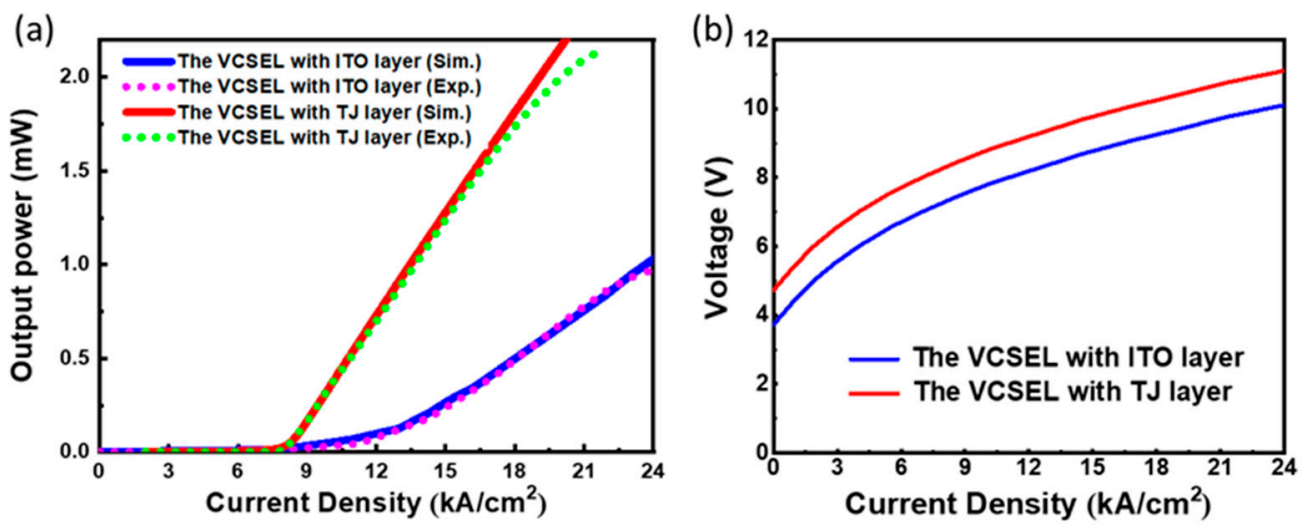

Figure 4. (a) Output power and (b) voltage versus current density of the VCSELs with conventional ITO and TJ structures.

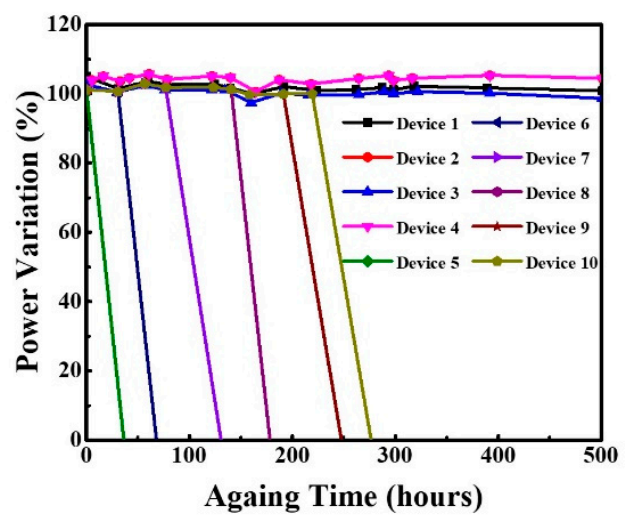

(a)

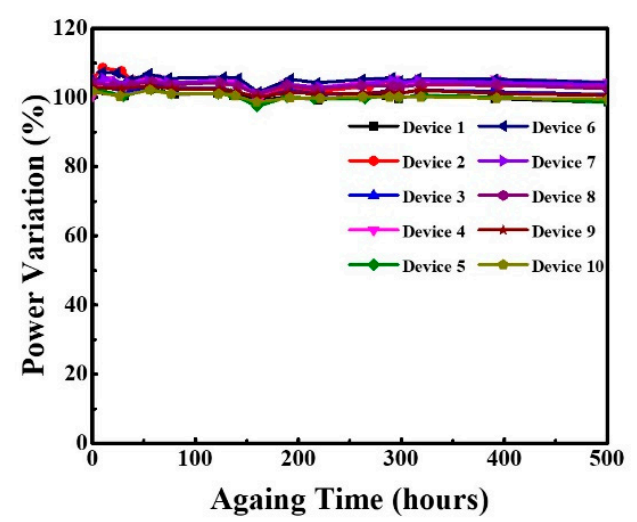

(b)

Figure 5. The HTOL $\left(70^{\circ} \mathrm{C} / 1.5 \times \mathrm{J}_{\text {th }}\right)$ performance of light output for VCSEL device with (a) ITO and (b) TJ structure.

\section{Conclusions}

In this study, we demonstrated an InGaN VCSEL with a TJ structure experimentally and theoretically. From simulation results, the optical loss of device can be reduced by a TJ structure. On the actual device performance, it was not only reduced in threshold current density but also improved the output power of the device. From the HTOL test, it passed over $500 \mathrm{~h}$. The results suggest weaker optical loss and better photoelectric properties using the TJ structure, which can be really useful for GaN optoelectronic and other commercial applications in the coming days.

Author Contributions: Conceptualization, Y.-W.Y.; Data curation, C.-Y.C.; Project administration, C.-W.S.; Software, Y.-T.L., Y.-T.C. and Y.-H.S.; Supervision, P.-T.L., T.-C.L. and H.-C.K.; Writing - original draft, C.-C.S.; Writing - review \& editing, T.W. and C.-H.C.

Funding: The authors would like to thank the Ministry of Science and Technology of Taiwan for their financial support.

Acknowledgments: The authors would like to thank Kenichi Iga and Fumio Koyama of Tokyo Institute of Technology, Shuji Nakamura of UC Santa Barbara, Connie Chang-Hasnain of UC Berkeley, Shing-Chung Wang of National Chiao Tung University, and Bo-Ping Zhang of Xiamen University for their insightful suggestions and discussions during the development of the GaN-based VCSEL technology.

Conflicts of Interest: The authors declare no conflict of interest. 


\section{References}

1. Bi, W.G.; Kuo, H.C.; Ku, P.C.; Shen, B. Handbook of GaN Semiconductor Materials and Devices; CRC Press: Boca Raton, FL, USA, 2017.

2. Schubert, E.F. Light-Emitting Diodes; Cambridge University Press: Cambridge, UK, 2018.

3. Wu, J.; Walukiewicz, W.; Yu, K.; Shan, W.; Ager Iii, J.; Haller, E.; Lu, H.; Schaff, W.J.; Metzger, W.; Kurtz, S. Superior radiation resistance of $\operatorname{In}_{1-x} \mathrm{Ga}_{\mathrm{x}} \mathrm{N}$ alloys: Full-solar-spectrum photovoltaic material system. J. Appl. Phys. 2003, 94, 6477-6482. [CrossRef]

4. Muth, J.; Brown, J.D.; Johnson, M.; Yu, Z.; Kolbas, R.; Cook, J.; Schetzina, J. Absorption coefficient and refractive index of GaN, AlN and AlGaN alloys. Mater. Res. Soc. Internet J. Nitride Semicond. Res. 1999, 4, 502-507. [CrossRef]

5. Michalzik, R. VCSELs: Fundamentals, Technology and Applications of Vertical-Cavity Surface-Emitting Lasers; Springer: Berlin, Germany, 2012; Volume 166.

6. Cheng, C.-H.; Shen, C.-C.; Kao, H.-Y.; Hsieh, D.-H.; Wang, H.-Y.; Yeh, Y.-W.; Lu, Y.-T.; Chen, S.-W.H.; Tsai, C.-T.; Chi, Y.-C. 850/940-nm VCSEL for optical communication and 3D sensing. Opto-Electron. Adv. 2018, 1, 180005. [CrossRef]

7. Iga, K. Forty years of vertical-cavity surface-emitting laser: Invention and innovation. Jpn. J. Appl. Phys. 2018, 57, 08PA01. [CrossRef]

8. Liu, A.; Wolf, P.; Lott, J.A.; Bimberg, D. Vertical-cavity surface-emitting lasers for data communication and sensing. Photonics Res. 2019, 7, 121-136. [CrossRef]

9. Mei, Y.; Weng, G.-E.; Zhang, B.-P.; Liu, J.-P.; Hofmann, W.; Ying, L.-Y.; Zhang, J.-Y.; Li, Z.-C.; Yang, H.; Kuo, H.-C. Quantum dot vertical-cavity surface-emitting lasers covering the 'green gap'. Light: Sci. Appl. 2017, 6, e16199. [CrossRef]

10. Yu, H.C.; Zheng, Z.W.; Mei, Y.; Xu, R.B.; Liu, J.P.; Yang, H.; Zhang, B.P.; Lu, T.C.; Kuo, H.C. Progress and prospects of GaN-based VCSEL from near UV to green emission. Prog. Quantum Electron. 2018, 57, 1-9. [CrossRef]

11. Dang, C.; Lee, J.; Breen, C.; Steckel, J.S.; Coe-Sullivan, S.; Nurmikko, A. Red, green and blue lasing enabled by single-exciton gain in colloidal quantum dot films. Nat. Nanotechnol. 2012, 7, 335. [CrossRef]

12. Kasahara, D.; Morita, D.; Kosugi, T.; Nakagawa, K.; Kawamata, J.; Higuchi, Y.; Matsumura, H.; Mukai, T. Demonstration of blue and green GaN-based vertical-cavity surface-emitting lasers by current injection at room temperature. Appl. Phys. Express 2011, 4, 072103. [CrossRef]

13. Lu, T.-C.; Kao, C.-C.; Kuo, H.-C.; Huang, G.-S.; Wang, S.-C. CW lasing of current injection blue GaN-based vertical cavity surface emitting laser. Appl. Phys. Lett. 2008, 92, 141102. [CrossRef]

14. Higuchi, Y.; Omae, K.; Matsumura, H.; Mukai, T. Room-temperature CW lasing of a GaN-based vertical-cavity surface-emitting laser by current injection. Appl. Phys. Express 2008, 1, 121102. [CrossRef]

15. Lu, T.-C.; Chen, S.-W.; Wu, T.-T.; Tu, P.-M.; Chen, C.-K.; Chen, C.-H.; Li, Z.-Y.; Kuo, H.-C.; Wang, S.-C. Continuous wave operation of current injected $\mathrm{GaN}$ vertical cavity surface emitting lasers at room temperature. Appl. Phys. Lett. 2010, 97, 071114. [CrossRef]

16. Hsieh, D.; Tzou, A.; Kao, T.; Lai, F.; Lin, D.; Lin, B.; Lu, T.; Lai, W.; Chen, C.; Kuo, H. Improved carrier injection in GaN-based VCSEL via AlGaN/GaN multiple quantum barrier electron blocking layer. Opt. Express 2015, 23, 27145-27151. [CrossRef]

17. Kuramoto, M.; Kobayashi, S.; Akagi, T.; Tazawa, K.; Tanaka, K.; Saito, T.; Takeuchi, T. High-output-power and high-temperature operation of blue GaN-based vertical-cavity surface-emitting laser. Appl. Phys. Express 2018, 11, 112101. [CrossRef]

18. Hamaguchi, T.; Tanaka, M.; Mitomo, J.; Nakajima, H.; Ito, M.; Ohara, M.; Kobayashi, N.; Fujii, K.; Watanabe, H.; Satou, S. Lateral optical confinement of GaN-based VCSEL using an atomically smooth monolithic curved mirror. Sci. Rep. 2018, 8, 10350. [CrossRef] [PubMed]

19. Leonard, J.; Young, E.; Yonkee, B.; Cohen, D.; Margalith, T.; DenBaars, S.; Speck, J.; Nakamura, S. Demonstration of a III-nitride vertical-cavity surface-emitting laser with a III-nitride tunnel junction intracavity contact. Appl. Phys. Lett. 2015, 107, 091105. [CrossRef]

20. Lee, S.; Forman, C.A.; Lee, C.; Kearns, J.; Young, E.C.; Leonard, J.T.; Cohen, D.A.; Speck, J.S.; Nakamura, S.; DenBaars, S.P. GaN-based vertical-cavity surface-emitting lasers with tunnel junction contacts grown by metal-organic chemical vapor deposition. Appl. Phys. Express 2018, 11, 062703. [CrossRef] 
21. Piprek, J. GaN-based vertical-cavity laser performance improvements using tunnel-junction-cascaded active regions. Appl. Phys. Lett. 2014, 105, 011116. [CrossRef]

22. Akyol, F.; Krishnamoorthy, S.; Zhang, Y.; Rajan, S. GaN-based three-junction cascaded light-emitting diode with low-resistance InGaN tunnel junctions. Appl. Phys. Express 2015, 8, 082103. [CrossRef]

23. Malinverni, M.; Martin, D.; Grandjean, N. InGaN based micro light emitting diodes featuring a buried GaN tunnel junction. Appl. Phys. Lett. 2015, 107, 051107. [CrossRef]

24. Skierbiszewski, C.; Muziol, G.; Nowakowski-Szkudlarek, K.; Turski, H.; Siekacz, M.; Feduniewicz-Zmuda, A.; Nowakowska-Szkudlarek, A.; Sawicka, M.; Perlin, P. True-blue laser diodes with tunnel junctions grown monolithically by plasma-assisted molecular beam epitaxy. Appl. Phys. Express 2018, 11, 034103. [CrossRef]

25. Zhang, Y.; Krishnamoorthy, S.; Johnson, J.M.; Akyol, F.; Allerman, A.; Moseley, M.W.; Armstrong, A.; Hwang, J.; Rajan, S. Interband tunneling for hole injection in III-nitride ultraviolet emitters. Appl. Phys. Lett. 2015, 106, 141103. [CrossRef]

26. PICS3D by Crosslight Software. Available online: www.crosslight.com (accessed on 24 October 2018).

(C) 2019 by the authors. Licensee MDPI, Basel, Switzerland. This article is an open access article distributed under the terms and conditions of the Creative Commons Attribution (CC BY) license (http:// creativecommons.org/licenses/by/4.0/). 